\title{
Towards a clearer understanding of student disadvantage in higher education: problematising deficit thinking
}

\author{
Reneé \\ Centre for Research in Engineering Education, Department of Electrical \\ Engineering, University of Cape Town, South Africa \\ renee.smit@uct.ac.za
}

This is an Accepted Manuscript of an article published by Taylor \& Francis in Higher Education Research \& Development, Vol. 31, No. 3(369-380), on June 2012, available online:

http://www.tandfonline.com/doi/abs/10.1080/07294360.2011.634383

\begin{abstract}
The combination of massification and increased diversity in student body pose particular challenges to higher education. The paper attempts to contribute to conversations around one of the 'silences' in higher education research - the uncritical use of 'disadvantage' discourse and its effect on pedagogic processes. It explores some of the challenges of coping with student diversity, with particular reference to a South African higher education context. Students enter higher education institutions with a variety of educational backgrounds, not all of which is considered to be sufficient preparation for the demands of higher education. The dominant thinking in higher education attempts to understand student difficulty by framing students and their families of origin as lacking some of the academic and cultural resources necessary to succeed in what is presumed to be a fair and open society. This constitutes a deficit thinking model: it focuses on the inadequacies of the student, and 'fixing' this problem. In the process the impact of structural issues is often ignored or minimised. Employing a deficit mindset to frame student difficulties acts to perpetuate stereotypes, alienate students from higher education and disregards the role of higher education in the barriers to student success. In the process universities replicate the educational stratification of societies. This paper suggests that we need to find more suitable responses to diversity in the student body. These require a change in our way of thinking: we need to thoughtfully consider the readiness of higher education institutions to respond to students, and cultivate the will to learn in our students. We need to find ways to research the full texture of the student experience and to value the pre-higher education context of students. In addition the notion of 'at risk' students could be helpful, and the original sense of the concept needs to be reclaimed.
\end{abstract}

Keywords: deficit thinking; student diversity; academic literacy

\section{Introduction}

Massification of higher education is a worldwide phenomenon. Globally higher education participation has grown from 19\% in 2000 to more than $26 \%$ in 2007, and in North America and parts of western Europe more than $60 \%$ of the age cohort is enrolled in higher education studies (Altbach, Reisberg, Rumbley, 2009). The same report predicts an increase in the diversity of higher education students as a key demographic trend for the period to 2030. It also expects a shift in national debates on higher education to include an increased consciousness of disadvantaged groups. The combination of massification and increased diversity in the student body pose particular challenges to higher education - "a sector long protected by high walls 
of selective entry and intellectual aloofness" (Northedge, 2003, p. 18) This paper explores some of the challenges of coping with student diversity in higher education, and with particular reference to a South African higher education context.

In South Africa over the past fifteen years there has been a commitment to increasing participation in higher education. However, even though access to higher education has to some extent been improved, participation remains highly skewed (Scott, Yeld and Henry, 2007). In order to address equity issues and wider diversity in the student population, higher education institutions have been implementing various measures to allow admission of students from previously disadvantaged backgrounds. ${ }^{1}$ Inadequate theorising around access policies often has unintended consequences for equity outcomes, and can serve to strengthen stereotypes of student ability. Many students enter higher education institutions with the product of what still amounts to inadequate schooling, and experience great difficulty with their studies. Understandably there are concerns around these gaps in skills and conceptual knowledge that students bring with them. However, 'disadvantage' has become an umbrella term to cover a wide array of perceived shortcomings, and has not been conceived of clearly.

The dominant thinking in higher education attempts to understand student difficulty by framing students and their families of origin as lacking the academic, cultural and moral resources necessary to succeed in what is presumed to be a fair and open society, and needing support from the dominant society or culture.

Much of the discussion around these topics concentrates on some aspect of deficiency: those who do not succeed in higher education fail because of some internal shortcoming (eg. cognitive or motivational), or some external weakness linked to the student (eg. cultural or familial background). It effectively blames the victim for lacking certain desirable characteristics that would promote academic success. Various terms are used in the educational literature to refer to this kind of approach: models of deficit thinking, cultural deprivation or inadequate socialization, and even the more recent construct of the 'at risk student'. They all have in common a focus on the inadequacies of the student, and 'fixing' this problem. When applied to education policies attempting to respond to student difficulties, it has been argued that deficit thinking amounts to a neo-liberal commitment to help those who cannot help themselves (Valencia, 1997)

In "The Evolution of Deficit Thinking" (Valencia, 1997) the authors trace the progression of the use of the deficit thinking model in explaining school failure, particularly among economically disadvantaged ethnic minority students in the USA. Menchaca (1997) argues that deficit thinking has its roots in early racist discourses in the USA: the belief that people of colour are biologically, intellectually and culturally inferior to people from so-called European descent. The implications of the conceptual model and its links to pedagogic practices over time are discussed. Valencia (1997) warns that deficit thinking is a 'protean' theory, taking on different

\footnotetext{
${ }^{1}$ The term "disadvantaged" refers to members of population groups in South Africa who under the Apartheid government have been deprived of an adequate school education. In the context of what this paper attempts to address, the term itself becomes problematic. However, in order to engage in this conversation, the author uses the term with reservation.
} 
forms to adapt to acceptable educational thinking of the day, and that it continues to impact on teaching policy and practice.

A more recent version of the protean deficit thinking model employs the concept of the "at-risk" student (Pellegrini, 1991). During the late 1980s the term "atrisk students" became widely used to describe students from disadvantaged backgrounds. It was initially introduced to counter the deficit thinking inherent in the description of disadvantaged students as 'culturally deprived'. The concept 'at-risk' has its origins in epidemiology in which medical professionals use statistics to identify vulnerable sections of the population to target for inoculation against disease. Intrinsic to the 'at risk' notion is the presumption is that it is possible to predict student failure, based on certain characteristics of the student. In terms of education, risk factors such as poverty, poor schooling, and limited English language proficiency, are often linked, and their effect has been described as multiplicative, rather than additive (Davis, 1996, Natrielo, in Levinson et al., 2002). Swadener and Lubeck (1995) challenge this, seeing it as inherently racist, classist, sexist and ablest in situating student difficulties firmly in the student, their families and the communities they come from. In many cases this becomes a self-fulfilling prophecy for students (They promote the idea of seeing students as facing real challenges and yet being 'at promise'. The task of higher education then becomes helping students realise those promises).

Boughey (2007) argues that the deficit model for educational development in South Africa in particular has strong roots in the historical situation that gave birth to it. She reminds us that the early Academic (Educational) Development Programmes in South Africa developed from historically white universities' refusal to submit to the apartheid government's attempts to control the numbers of black students who would be allowed into higher education. Early student support programmes therefore had an essentially liberal agenda, and were aimed at giving black students a fair chance of success in higher education institutions. 'Disadvantage' and underpreparedness were considered to be factors inherent to black students: they lacked the required language and social skills, as well as the conceptual background to take on higher education, and so support programmes were developed to remedy the inadequacies. These support programmes often were in the form of adjunct courses outside the mainstream offering. Implicit in these was the uncritical acceptance of the dominant culture of higher education: the intention was for black students with potential to be assisted to become part of this dominant culture. This would lead to replication of the dominant culture. In the language of discourse (Gee, 1996) black students were expected to take on the ways of being in the world that mark them as members of the typical university student body.

\section{Why is deficit thinking problematic?}

In some ways there is a commonsense appeal to deficit thinking: students enter higher education with real shortcomings, and a programme is developed to bridge the gap between prior schooling and university. What are some of the fundamental difficulties with this kind of thinking?

\section{The injustice of stereotypes}


One of the most serious effects of deficit thinking is that it strengthens stereotypes in the minds and thought of educators, policy makers and students themselves. In essence deficit thinking allows generalisations about student ability to be made, and supports a laziness to grapple with the complex issues around student difficulties. In the process people who are already disenfranchised are labelled and further stigmatised.

\section{Low teacher expectations and pedagogic disadvantage}

Garcia and Guerra (2004) point out that deficit thinking disguises lowered teacher expectations, and impacts on teaching practice. In a study on variations in mathematical instruction in South African high school classrooms, Swanson (2002) also describes the way in which dichotomies are set up between 'successful' and unsuccessful' students in terms of social differences between students (for example gender, class, race, culture, language differences). Deficit thinking produces and (eventually) reproduces these differences between students in the learning context. Swanson describes how the social differences are recontextualised as disadvantage, establishing 'truths' about students from disadvantaged communities. This finds its outworking in pedagogic practices that limit access to the regulative discourse of the mainstream mathematics: "constructed disadvantage begot pedagogic disadvantage" (p. 1474). What is particularly disturbing in the scenario described, is the way in which disadvantage is 'refracted' or recontextualised as low academic ability, and how it is then worked out in pedagogic practices. The effect of this is an inevitable societal reproduction as the consequence of education. Using Bernstein's terms, the academic support programme in mathematics described in the study is weakly classified and framed, and reinforces notions of disadvantage rather than contest it (Swanson, 2002). It is easy to see how power relations are set up that students experience as disempowering rather than enabling (Mann, 2008).

\section{Alienation}

The effect of the deficit thinking model on students is devastating. Tema (1985) points out that the students from disadvantaged backgrounds who get to university, see themselves as survivors of an inferior schooling system, as strong, successful individuals who have beaten the system, and who, in many cases, carry with them the hopes and dreams of families they leave behind. These students arrive at higher education institutions and are told, in effect, that they stand very little chance of succeeding, that they are lacking in a number of aspects, and that they have to 'catch up'. They are marked and separated from the 'mainstream' by virtue of their deficiency, and their 'other-ness' is reinforced. In these ways students are in effect alienated from the very system they have worked hard to be part of.

\section{Structural factors and 'commonsense'}

Another problem with deficit thinking, is that it focuses on educational policies that attempt to instil missing qualities (conceptual knowledge, skills, life skills etc.). A great deal of educational development in South Africa focuses on agentic discourse the response that should be encouraged in the lacking student -- and neglecting the very real effects of the structural injustice of inferior prior education (Davis, 1996). 
Even if there is at some abstract level a nod towards recognising the consequence of inferior schooling, the concrete, tangible effect of external structural factors like inequality in schooling resources (like computers, internet and library access, untrained teachers), inflexible teaching and assessment strategies and oppressive policy decisions, are not taken seriously. There is also a danger that in labelling students as disadvantaged, lecturers are absolved from blame/ responsibility when considering teaching and learning interactions.

In a related issue, Boughey (2002) points out the danger of relying on commonsense notions (as opposed to sound theory and research) about students from disadvantaged backgrounds. Many of these commonsense ideas (such as 'disadvantaged students struggle with the concepts in academic courses because of their poor command of English') have strong ideological foundations and reinforce the deficit thinking model that student difficulties can be attributed to innate differences in cognition.

\section{Are there more appropriate ways to reflect on educational disadvantage?}

How does one then proceed? The reality of the difficulties faced by underprepared students cannot be denied. Neither can the dilemma faced by higher education institutions. If an institution intends to produce highly skilled graduates and takes in students to address equity profiles, these issues have to be grappled with. What follows here are not simple solutions to the problem - there are none. The challenge is complex and any suggestions on how to proceed will have to be multifaceted. I want to propose that what is most needed to begin to address the problems of underprepared students, is a change of perspective, hinted at by a number of theoretical constructs discussed next.

\section{Take on board the concept of academic literacy}

Contemporary educational and sociological theories (by theorists like Gee, Bourdieu and Vygotsky) allow an alternative explanation for student experience in terms of literacy and discourse (Gee, 2001): learning and teaching are seen as socially embedded practices, and not as neutral activities. These theories make it possible to move away from deficit thinking and get to the heart of the problem: disadvantaged students are outsiders to the discourses of academia and unfamiliar with what is valued in higher education. Interventions based on deficit assumptions (such as 'fixing' students' language inadequacies through adjunct language courses) only have limited success because they address secondary problems. What students need is access to the 'ways of being' in the disciplines that take into account 'what matters' in higher education. This is a form of literacy that is broader than language use. Gee (1996) calls it the Discourse of the discipline, Bernstein (2000, p.29) access to the 'unthinkable', and Morrow (2009) 'epistemological access': for students to become participants in academic practice, they need to 'understand and care about the relevant epistemic values' (p. 46) of the discipline they're studying. This can only happen if the relevant values and Discourses are made explicit in teaching, and if a community is created into which students are welcomed (Mann, 2008).

\section{Nurture the will to learn}

In his book, A will to Learn, Barnett (2007) makes a powerful argument for what he calls an 'ontological turn' (p.9) in our thinking about students in higher education. He 
believes that the will to learn is the most important educational concept, and focuses his attention on how it is that students persist in higher education, rather than on why students fail. And this maybe gives us a clue to a different way of thinking. The successful disadvantaged student has a wealth of information we need to tap into to understand how it is that some of these students flourish in higher education.

The will to learn is different from motivation: it is internal to the student and more general than motivation. Barnett believes that an exclusive emphasis on the knowledge \& skills agenda in higher education provides us with only two pillars - the epistemological and practical pillars - and that we need a third pillar, ontology, to build higher education on a stable foundation. The ontological approach brings back the student into our conversations about higher education; Barnett believes that there is a real danger of objectifying the student or to only see students en masse in our current conversations in higher education. This happens when we refer to students only in terms of social equity (access and success), as units of resource or cost (throughput issues), sources of income (fees) or as eventual economic participators (employability, graduate attributes). Barnett argues for a different vocabulary to be used; what he calls a suitable vocabulary. It employs terms like will, energy, engagement, being and becoming, passion, self-confidence, journey, travel. He believes that we are in desperate need of thinking and practices in higher education that take the student as human being seriously. In a resonance with theorists like Gee (1996), Barnett describes the being of the student as 'the way the student is in the world' (p. 27). This being is at the same time both durable and fragile, and educators need to be aware of this. A true higher education involves a transformation of the student being. This transformation is complex, because it does not simply mean a change from one mode of being to another kind of life, but it involves the taking on of a "mode of being for uncertainty" (Barnett, 2007, p. 39), for living with contested knowledge. Again, there is a ring here of the thoughts of other social theorists in the idea of acquiring a Discourse to gain secondary literacies (Gee, 1996).

In the context of this paper, this is a challenge to us to reconsider our ideas around disadvantage. Are we not guilty of objectifying students when we label them as disadvantaged? The emphasis is certainly on throughput issues in our conversations about disadvantage. Do we take full cognisance of the student's will to learn when we employ deficit models of thinking? What are the pedagogical implications for tapping into this will to learn? To what extent do we diminish the 'will to learn' when our pedagogic practices separate and alienate students from a process that should be about enabling, about becoming?

\section{Recover the essence of the idea of at-risk students}

In the earlier discussion of the protean nature of deficit models, concerns were raised about the way in which the idea of at-risk students has been distorted into a form of deficit thinking. However, the emphasis on early recognition of students most likely to experience difficulties is a compelling diagnostic tool, especially with large intakes of students. Taking the medical origin of the term into account, implicit in its use in education should be an appreciation of the differential susceptibility to the impact of a combination of personal and environmental factors on student success (Natriello, in Levinson et al., 2002). Not all students who come from academic disadvantage experience the same difficulties in higher education. If we could recover this understanding of differential susceptibility to structural environmental factors, and 
embrace the appropriate tentativeness implied in the term, we could gain a powerful conceptual understanding of underprepared students. One could conceive of the important role mentors could play in supporting at-risk students.

\section{Insist on rich investigations rather than commonsense notions}

How should we then go about infusing these ideas in practice - is it even possible to test some of these in pedagogical practice? I have already noted Boughey's (2002) concern that certain commonsense notions of what should be 'done' with disadvantaged students carry with them the danger of oversimplification and of misuse of education theories. Barnett (2007) suggests the idea of a 'muted empiricism' (p.5) that could be deployed in researching: We glimpse reality with our senses and imaginations, 'with our hopes and even passions... However, the stories that emerge should not be totally fanciful; rather, they should be testable and tested against experience... The ideas may have a utopian quality ... but they should have an empirical potential, being capable of being taken up perhaps as resources for imaginative actions' (p.4,5). A hint of this kind of empiricism and rich investigation can be found in a study done by Marshall and Case (2010). The researchers used a narrative analysis to explore the particular resources disadvantaged students bring with them into higher education, and how these could be harnessed in identity construction. Again this brings a shift in perspective to reflection on the successful 'disadvantaged' student.

\section{Acknowledge the university as possibly an underprepared institution}

There is a sense in which higher education institutions themselves are underprepared for meeting the needs of the changing student body. Boughey (2007) describes the arguments made in the 1990s calling for a different perspective of situating disadvantage in the structures that act on individuals --'structural disadvantage' (Hutchings and Garraway, 2010, 6), rather than in the students themselves. Haggis (2006) calls for a reconceptualisation of the "barriers to learning" model in which higher education would consciously critique and challenge those activities and patterns of communication in its pedagogical culture that make it difficult for some students to learn.

The time has come for higher education institutions to move beyond discussions about access for disadvantaged students and special programmes for underprepared students. Educational development has to move from the provision of entrance or bridging programmes to being infused in mainstream academic teaching. And although this kind of conversation has been taking place in terms of the changes in university policies around Academic (Educational) Development Programmes (Boughey, 2007), a strong argument could be made that for many mainstream academics this is still not a consideration, that student development has not moved from the periphery to the core business of academia. Many academics hold a "defensive cynicism” (Haggis, 2006, p. 523) which associates widening access with an inevitable loss of higher education standards. The only way change will come, will be if we find ways to challenge some of the dominant discourses in our institutions

\section{Value diversity and recognise what students bring to higher education}


Massification of higher education has brought about an increase in the diversity of students. This diversity is evident in student backgrounds: socio-economic status, language, cultural and educational background. It is a feature of globalisation and increased mobility. All higher education institutions need to value this diversity, tap into its riches and work out how to make differentiated learning possible. Tema (1985) argues for much more nuanced research into student background and argues strongly against the convenience of labels. Labels hide unidentified, unexamined assumptions; we need to know what good things students learn from their disadvantaged backgrounds (see also Marshall and Case, 2010). Deficit thinking applies a narrow pathology-seeking assessment to groups of people, and fails to recognise individual strengths. Academic staff need to actively search for ways to tap into student competences, and find ways to recognise what Sacks (2002, p.45) calls 'the dignity of difference'.

\section{Conclusion}

Across the world the demographics, conceptual background, skills, values and attitudes of students entering higher education have been changing. The increasing focus on market forces in allocating places in mass higher education systems challenges selection criteria that are used to encourage access from previously excluded categories of students. Quality assurance agendas demand a sober assessment of throughput and graduation rates. The weight of these arguments is unlikely to diminish in the foreseeable future. In addition, the challenges are in tension with conversations about education for the public good, conversations about democratic education, graduate capabilities, and even education for poverty alleviation.

It is important that higher education grapples with ways in which to address the very real challenges faced by students from academically diverse backgrounds. Describing 'disadvantage' primarily in terms of poverty or socio-economic status, gives an under-nuanced perspective. Employing a deficit mindset to frame student difficulties acts to perpetuate stereotypes, alienate students from higher education and disregards the role of higher education in the barriers to student success. In the process universities serve to replicate the educational stratification of societies.

This paper suggests that we need to find more suitable responses to diversity in the student body. These require a change in our way of thinking: we need to carefully and thoughtfully consider the readiness of higher education institutions to respond to students, and cultivate the will to learn in our students. We need to find ways to research the full texture of the student experience and to value the pre-higher education context of students. In addition the notion of 'at risk' students could be helpful, and the original sense of the concept needs to be reclaimed.

Perhaps this is one of the contributions 'voices from the South' can make in conversations around one of the 'silences' in higher education - the uncritical use of 'disadvantage' discourse and its direct effect on pedagogic processes. In the South African context the voices may be more strident, the realities starker, and the political pressure more adamant, but the need for higher education to find a way to respond to the very real issues faced by diverse incoming students, without succumbing to deficit thinking can hardly be overstated. 


\section{References}

Altbach, P., L. Reisberg, L., Rumbley, L.E. (2009). Trends in global higher education: Tracking an academic revolution. A report prepared for the UNESCO 2009 World Conference on Higher Education. UNESCO.Paris.

Barnett, R. (2007). A will to learn: being a student in an age of uncertainty. Maidenhead. Open University Press/Society for research into Higher Education. (McGraw-Hill Education).

Bernstein, B. (2000). Pedagogy, symbolic control and identity: theory, research, critique. Rowman \& Littlefield Publishers, Inc. New York.

Bertram, C., Appleton, S., Muthukrishna, N., Wedekind, V. (2006). The career plans of newly qualified South African teachers. South African Journal of Education. 26(1), p.1-13.

Boughey, C. (2002). 'Naming' students' problems: an analysis of language-related discourses at a South African University. Teaching in Higher Education, 7(3),295-306.

Boughey, C. (2007). Educational development in South Africa: From social reproduction to capitalist expansion? Higher Education Policy, 20, 5-18.

Davis, W.E. (1996). Children and Families 'At Promise': A Laudable but Potentially dangerous Construct. Paper presented at the Annual Meeting of the American Psychological Association, $\left(104^{\text {th }}\right.$, Toronto, Ontario, Canada, August 9-13, 1996). Accessed online at http://eric.ed.gov/PDFS/ED406638.pdf on 2 July2010.

Garcia, S.B. \& Guerra, P.L. (2004). Deconstructing Deficit Thinking: Working With Educators to Create More equitable Learning Environments. Education and Urban Society.36 (2), 150-168.

Gee, J.P. (1996). Social Linguistics and Literacies: Ideology in Discourse. Routledge. London.

Gee, J.P. (2001). Identity as an Analytical Lens for Research in Education. Review of Research in Education. 25, 88-125.

Haggis, T. (2006) Pedagogies for diversity: retaining critical challenge amidst fears of 'dumbing down'. Studies in Higher Education, 31(5), 521-535.

Hutchings, C and Garraway, J. (eds.). (2010). Beyond the university gates: Provision of Extended Curriculum Programmes in South Africa. Higher Education Teaching and Learning in Southern Africa (HELTASA). Accessed online at http://associated.sun.ac.za/heltasa/ on 13 July 2010.

Levinson, D., Cooksen, P.W., Sadovnik, A.R (eds.). (2002). Education and Sociology: an encyclopedia. RoutledgeFalmer. New York.

Mann, S. (2008). Study, Power and the University. Maidenhead. Open University Press/Society for research into Higher Education. (McGraw-Hill Education).

Marshall, D. \& Case, J. (2010). Rethinking “disadvantage’ in higher education: A paradigmatic case study using narrative analysis. Studies in Higher Education, 35(5), 491-504.

Menchaca, M. (1997). Early racist discourses: roots of deficit thinking. In R.R. Valencia (Ed.), The Evolution of Deficit Thinking: Educational Thought and Practice. (13-40). The Falmer Press. London.

Morrow, W. (2009). Bounds of Democracy: Epistemological Access in Higher Education. Human Sciences Research Council Press. Cape Town.

Northedge, A. (2003). Rethinking teaching in the context of diversity. Teaching in Higher Education, 8(1), 17-32.

Pellegrini, A.D. (1991). A Critique of the Concept of At Risk As Applied to emergent Literacy. Language Arts, 68 (5), 380-385.

Scott, I., Yeld, N., \& Hendry, J. (2007). A case for improving teaching and learning in South African higher education. Higher Education Monitor No. 6. Council on Higher Education.

Swadener, B.B. \& Lubeck, S. (eds.). Children and families 'at promise': Deconstructing the discourse of risk. State University of New York Press. Albany, NY.

Swanson, D. (2002). 'Disadvantage' and school mathematics: The politics of context. International Journal of Learning, 9, 1471-1480.

Sacks, J. (2002). The Dignity of Difference: How to Avoid the Clash of Civilizations. Continuum. London.

Tema, B. (1985). Academic support: Its assumptions and its implications. South African Journal of Higher Education , 2 (1), 29-31.

Valencia, R (Ed.). (1997). The Evolution of Deficit Thinking: Educational Thought and Practice. The Falmer Press. London.

Vilakazi, H. \&. Tema, B. (1985). White universities and the black revolution. ASPects: Journal of the Academic Support Programmes at the University of Cape Town, the University of Natal, Rhodes University and the University of the Witwatersrand , 6, 18-40. 